\title{
What Best Protects the Inverted Weightbearing Ankle Against Further Inversion?
}

\section{Evertor Muscle Strength Compares Favorably with Shoe Height, Athletic Tape, and Three Orthoses}

\author{
James A. Ashton-Miller, ${ }^{\star} † \mathrm{PhD}$, Robert A. Ottaviani,‡ Christopher Hutchinson, $\neq$ \\ and Edward M. Wojtys, $\neq$ MD
}

\begin{abstract}
From *Biomechanics Research Laboratory, Department of Mechanical Engineering and Applied Mechanics, Department of Biomedical Engineering, and Institute of Gerontology and $¥$ MedSport, Section of Orthopaedic Surgery, University of Michigan, Ann Arbor, Michigan
\end{abstract}

\begin{abstract}
We measured the maximal isometric eversion moment developed under full weightbearing in 20 healthy adult men (age, $24.4 \pm 3.4$ years; mean \pm SD) with their ankles in $15^{\circ}$ of inversion. Tests were performed at both $0^{\circ}$ and $32^{\circ}$ of ankle plantar flexion in low- and in three-quarter-top shoes with and without adhesive athletic tape or one of three proprietary ankle orthoses. At $0^{\circ}$ of ankle plantar flexion, the mean maximal voluntary resistance of the unprotected ankle to an inversion moment was $50 \pm 8 \mathrm{~N}$-m; this increased by an average of $12 \%$ (or $6 \mathrm{~N}-\mathrm{m}$ ) when the subject wore a threequarter-top basketball shoe. The maximal voluntary resistances to inversion moments developed with the ankles further protected by athletic tape or any of three orthoses were not significantly different. Biomechanical calculations suggest that at $15^{\circ}$ of inversion the fully active ankle evertor muscles isometrically developed a moment up to six times larger than that developed when an athlete wears a three-quarter-top shoe alone and more than three times larger than that developed passively when the athlete has tape or an orthosis worn inside a three-quarter-top shoe. We conclude that fully activated and strong ankle evertor muscles are the
\end{abstract}

† Address correspondence and reprint requests to James A. Ashton-Miller PhD, Biomechanics Research Laboratory, Department of Mechanical Engineering and Applied Mechanics, 3208 G.G. Brown Building, University of Michigan, Ann Arbor, MI 48109-2125.

No author or related institution has received any financial benefit from research in this study. See "Acknowledgments" for funding information. best protection for a near-maximally inverted ankle at footstrike.

Ankle injuries are common in sports, ${ }^{44,50}$ accounting for up to $25 \%$ of all time lost from competition. ${ }^{29}$ The dominant limb is involved in ankle injuries more than twice as often as the nondominant limb. ${ }^{50}$ Most ankle injuries are the inversion type and occur during landing, ${ }^{7}$ particularly with the foot in plantar flexion and internally rotated, ${ }^{12,13}$ a position in which the anterior talofibular ligament is subject to the greatest amount of strain. ${ }^{6}$ Some of these injuries can be debilitating and costly in terms of time lost from training or competition. Several forms of ankle protection have been developed to reduce the risk of injury, including high-top athletic shoes, athletic taping, ${ }^{9}$ and a plethora of orthotic devices. ${ }^{3,10}$

Athletic taping has long been a popular prophylaxis because it is convenient to use and because of the traditional beliefs of athletes, trainers, and coaches that taping is an effective form of ankle protection. The most basic function of athletic tape is to restrict the range of ankle motion to prevent extreme and injurious ankle motions ${ }^{11,26,32,37,40}$; tape acts, in essence, as an external ligament. ${ }^{16,26}$ Some authors have proposed that tape can shorten the reaction time of the peroneal muscles to an inversion movement by augmenting sensory input. ${ }^{15,22}$ Whether tape affects the active resistance to inversion provided by the ankle evertor muscles is unknown.

With the advantages of taping, however, come several disadvantages. The decrease in ankle passive range of motion due to taping can affect functional performance in 
certain activities., 20,21,29,31 For example, both taping and orthoses have been found to significantly and adversely affect postural control in tests of unipedal balance. ${ }^{2}$ In addition, the repeated daily application of tape in an athletic setting can be costly because it requires experienced personnel. ${ }^{39}$ The repeated removal of adhesive tape can cause skin irritation. Finally, tape may lose its effectiveness with prolonged athletic activity ${ }^{31}$; up to a $40 \%$ decrease in the ability of tape to restrict ankle range of motion has been noted after as little as 10 minutes of exercise. ${ }^{11,15,16,26,40}$

Because of these problems, ankle orthoses have become popular alternatives to athletic taping, with examples including canvas lace-up stabilizers and semirigid moldedplastic models. Orthoses are popular because they are easy for the athlete to apply, they can be tightened as needed during competition, and they cause little skin irritation. These devices can be as effective as tape in restricting extreme ranges of passive ankle motion. ${ }^{16,18,19}$ For example, Shapiro et al. ${ }^{42}$ showed that high-top athletic shoes significantly increased the passive resistance provided by taping and bracing when they were compared with low-top shoes, but they found no difference between the increases provided by taping or bracing.

Most, but not all, epidemiologic studies suggest that high-top shoes, athletic tape, and orthoses are effective in reducing the incidence of ankle injuries, although the benefits depend on the sport. Rovere et al. ${ }^{41}$ reported that football players who used low-top shoes with ankle stabilizers had the fewest ankle injuries. Garrick and Requa, ${ }^{14}$ on the other hand, found the lowest ankle injury rates among basketball players using high-top shoes and athletic tape, and Barrett et al. ${ }^{1}$ found no significant differences between the use of low- and high-top basketball shoes in preventing ankle sprains. Surprisingly, it is unknown how much protection any of these devices offer compared with the resistance developed by the eversion ankle musculature at footstrike when the ankle is resisting further inversion of an ankle actively placed in nearmaximal inversion. That question is the focus of this paper. To avoid the risk of injuring study participants, we approached this question by using quasistatic, rather than dynamic, experimental testing with a simple biomechanical analysis.

The first goal of this research was to measure the maximal isometric eversion moment that young male adults can develop volitionally with the weightbearing foot in $15^{\circ}$ of inversion. The next goal was to test the null hypothesis that no difference would be found in the maximal overall eversion moment developed whether athletic taping or one of three different ankle orthoses was worn inside a low-top or a three-quarter-top basketball shoe. Tests were conducted at near-maximal inversion ( $15^{\circ}$ of inversion) with $0^{\circ}$ or $32^{\circ}$ of ankle plantar flexion, thus encompassing a range of foot orientations existing just before an ankle inversion injury and at angles in which these prophylactic devices should be effective. The final goal was to use a simple biomechanical model, together with published results of ankle stiffness during weightbearing, to test the hypothesis that the evertor muscles may provide greater resistance to large external inversion moments than three-quarter-top basketball shoes, athletic taping, or ankle orthoses at near-maximal inversion.

\section{MATERIALS AND METHODS}

\section{Subjects}

We recruited 20 healthy, young adult men aged $24.4 \pm 3.4$ years (mean $\pm \mathrm{SD}$ ) with no ankle injuries in the 6 months before testing. All subjects wore size 10 athletic shoes. Leg dominance ( 19 of 20 subjects preferred to kick a ball with their right foot), weight $(827 \pm 110 \mathrm{~N})$, and ankle height (medial and lateral malleoli) from the floor were recorded.

\section{Unipedal Strength Test}

We tested the functional eversion ankle strength of each subject under full weightbearing conditions with the ankle in near-maximal inversion ( $15^{\circ}$ inversion) and in $0^{\circ}$ or $32^{\circ}$ of plantar flexion using a specially designed testing apparatus (Fig. 1). The testing apparatus and methods are described elsewhere and have been used by us to measure young adult ankle inversion and eversion strengths in the neutral ankle position. ${ }^{38}$ Briefly, the apparatus consisted of a size 10 shoe securely fastened to a $1.5-\mathrm{cm}$ thick, $36 \times$

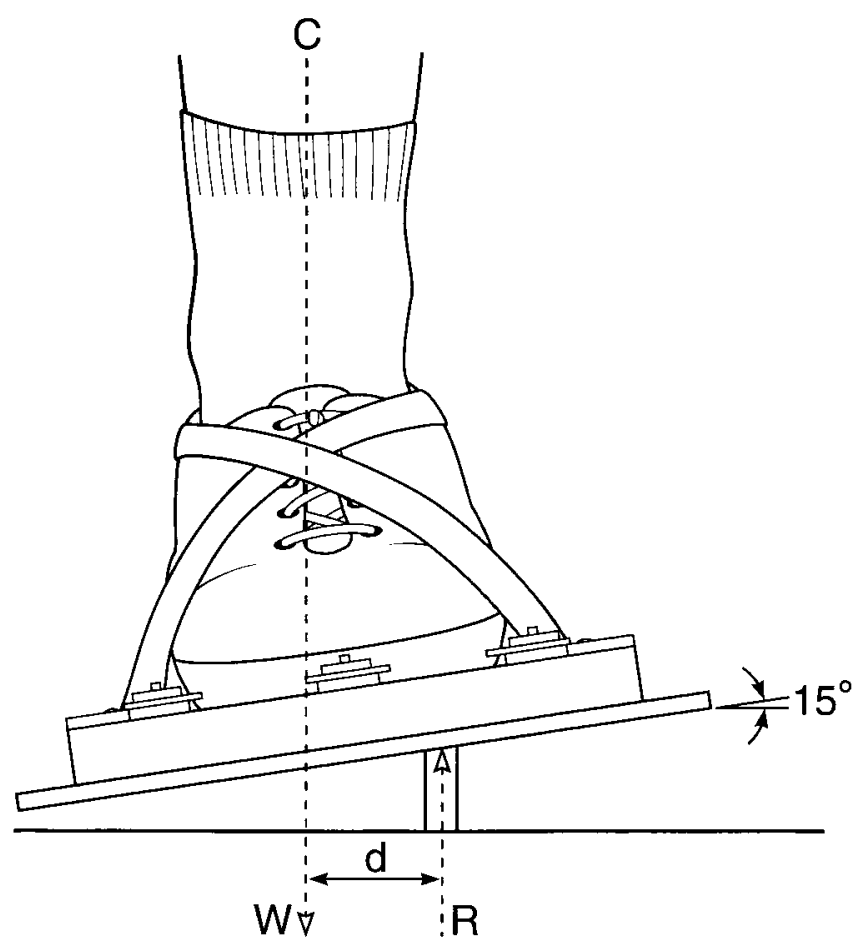

Figure 1. Schematic diagram of how the maximal volitional resistance to inversion was measured at near-maximal inversion. The ground-reaction force of $1 \mathrm{BW}(\mathrm{R})$ acted with a lever arm (d) medially about the subtalar joint center, through which the vertical reference line (C) passes. The maximal value of the lever arm was found at the point at which subjects could balance full body weight for 2 seconds. 
$20 \mathrm{~cm}$ footplate. Eight metal clamps distributed around the perimeter of the shoe gripped the edge of the shoe's sole and heel. Under the footplate was a track accommodating a $40-\mathrm{cm}$ long, $5 \times 10 \mathrm{~mm}$ steel bar positioned in the frontal plane under the fifth metatarsophalangeal joint. A centimeter scale was located on top of the steel bar, and midway along it the bottom of the bar had a $13-\mathrm{mm}$ diameter circular recess drilled at a $15^{\circ}$ angle to accommodate the top end of a $15-\mathrm{mm}$ high, $12-\mathrm{mm}$ diameter, vertical, fixed steel peg screwed firmly into a large steel plate at its base.

After the bar was positioned under the fifth metatarsophalangeal joint, each participant placed his right foot in the shoe of the apparatus. The laces were then tightened in a controlled manner to $45 \mathrm{~N}$ of tension. The steel peg was initially positioned $7 \mathrm{~cm}$ medial to the subtalar ankle axis in the frontal plane. With their ankles in $15^{\circ}$ of inversion, the participants were asked to balance unipedally on the device for a minimum of 2 seconds. Initially, use of a support bar was allowed. Once balance was achieved, finger support was removed and participants attempted to maintain the initial $15^{\circ}$ of inversion $\left( \pm 5^{\circ}\right)$ for 2 seconds. The peg height was set so that once the initial $15^{\circ}$ of inversion was established, deviation by more than $5^{\circ}$ would cause the testing device to touch the ground to prevent injury and to electronically signal a loss of balance.

The test began when the participant released the support bar and ended if either the testing device or any part of the subject touched the ground or support bar. Balancing for 2 seconds with less than $5^{\circ}$ of deviation from the starting position was considered a successful test; failure to do so was noted as an unsuccessful test. Three attempts were allowed. If all attempts were unsuccessful, the steel peg was moved in 1-cm increments toward the center of the ankle until a successful trial was completed. After the first successful trial, adjustments of $0.25 \mathrm{~cm}$ were made toward the medial peg until the authors identified the most medial test position successfully tolerated. All tests of eversion strength were repeated with a $32^{\circ}$ wedge under the posterior two-thirds of the foot to determine the effect of ankle plantar flexion on ankle strength.

To quantify the effect of shoe height, testing was performed with a low-top basketball shoe (Nike Air Force I; Nike Inc., Beaverton, Oregon) and a three-quarter-top basketball shoe (Nike Air Force Max) while the ankle was unprotected. To quantify the effect of tape, these tests were repeated after the ankle was taped in a standard manner. The 1.5-inch wide cloth tape (Zonas tape; Johnson \& Johnson, Inc., Skillman, New Jersey) was applied using adhesive spray, foam prewrap, and a closed basket weave with four stirrups reinforced with two figure-of- 8 and two "heel-lock" patterns. Finally, to quantify the effect of selected orthoses, tests were repeated with a Swede-O ankle brace (Swede-O-Universal, North Branch, Minnesota), Air-Stirrup, and Sport-Stirrup (each from AirCast, Inc., Summit, New Jersey). The individual braces were fitted according to the manufacturer's directions. The sequence for testing in the low- and three-quarter-top shoes, in the different orthotic states, at the two positions $\left(0^{\circ}\right.$ and $32^{\circ}$ of ankle plantar flexion) was randomized and randomly varied between subjects.

Because the low-top shoe does not extend above the ankle joint, that particular shoe design can offer no passive resistance to ankle inversion. The maximal voluntary resistance to inversion moments actively developed by the evertor muscles with the low-top shoe was therefore used as the "unprotected" basis for comparison with the resistance developed when using the three-quarter-top shoe with and without athletic tape or with one of the three orthoses.

To determine the external moment applied by body weight (BW) about the subtalar ankle joint, it was necessary to determine the distance $(d)$ of the center of gravity of the whole body, acting through the peg centerline, from the subtalar joint "center" when the participant is balanced unipedally on the peg. If $\mathrm{L}$ is the distance measured from the centimeter scale, $d$ can be found from the following formula:

$d=\left[\mathrm{L}^{*} \cos \left(15^{\circ}\right)\right]+$

$\left\{(\text { ICR height }+ \text { footplate thickness })^{*} \sin \left(15^{\circ}\right)\right\}$

where $d$ equals distance and ICR equals instantaneous center of rotation.

The height of the midpoint of the functional subtalar joint was assumed for simplicity to coincide with its instantaneous center of rotation in inversion. This was determined using three posteroanterior radiographs taken of five healthy young men while standing on a surface in one of three orientations: horizontal and at $10^{\circ}$ and $20^{\circ}$ of inversion. Lead markers were placed on each maleollous, the anterior tibial surface, the distal portion of the calcaneous, and the medial sustentaculum tali and the lateral peroneal trochlea of the foot. On each radiograph the perpendicular bisector to the two latter points was drawn. After superimposing the supratalar marker images, the location for the subtalar instantaneous center of rotation was found midway between the intersections of the three perpendicular bisectors. The distance of the subtalar instantaneous center of rotation below the medial malleolus was then determined and scaled to compensate for radiographic magnification. The mean relative height of the subtalar instantaneous center of rotation above the support surface was $19 \%$ less than that of the average bimalleolar height. Although we recognize that the instantaneous center of rotation does not necessarily reflect the equivalent point of load transmission in the subtalar joint, it does provide a reasonable approximation for the center of an equivalent hinge joint in the frontal plane. Because the sine function is evaluated at $15^{\circ}$ and the mean instantaneous center of rotation height was only $8.8 \pm 0.7 \mathrm{~cm}$, any reasonable errors in estimation of this equivalent "joint" height have a minor effect on the magnitude of $d$.

\section{Estimation of Baseline Ankle Resistance to an Inversion Moment at $15^{\circ}$ of Inversion}

The baseline resistance of the ankle joint to inversion was not measured in this investigation because it has already 
been measured during full weightbearing in a group of nine young healthy men (mean weight, $76.8 \pm 9.8 \mathrm{kgf}$; mean height, $1.78 \pm 0.79 \mathrm{~m}$ ) while they stood unipedally, without shoes, tape, or orthoses, with the foot clamped firmly into a servo-driven test apparatus. ${ }^{27}$ The joint stiffness in forced inversion measured in that study, using the subject instructions "do not voluntarily intervene" by using your muscles to prevent the ankle rotation of up to $9^{\circ}$ of inversion, had a mean value of $0.97 \pm 0.23 \mathrm{~N}-\mathrm{m} / \mathrm{deg}$. This value is consistent with the average joint stiffness of $0.9 \mathrm{~N}-\mathrm{m} / \mathrm{deg}$ also measured during full weightbearing in six young healthy adults during $35^{\circ}$ of forced dynamic inversion..$^{36}$ Assuming linear stiffness behavior up to $15^{\circ}$ of inversion rotation, which is not an unreasonable assumption given the results of Chen et al., ${ }^{5}$ one can use these values to calculate that the average eversion moment developed by the combination of passive tissue stretch on the lateral aspect of the leg and postural muscle activity in the peroneal muscle group during full weightbearing at $15^{\circ}$ inversion in young men is approximately 14 $\mathrm{N}-\mathrm{m}(13.5 \mathrm{~N}-\mathrm{m}$ derived from reference $36 ; 14.6 \mathrm{~N}-\mathrm{m}$ derived from reference 27). For the purpose of this study, we termed $14 \mathrm{~N}-\mathrm{m}$ the "baseline" moment developed while weightbearing at $15^{\circ}$ inversion because it involves principally the passive resistance caused by inverting the ankle from $0^{\circ}$ to $15^{\circ}$ as well as the resistance provided by any postural ankle muscle activity required to simply balance on one foot.

\section{Estimation of Passive Device and Active Muscular Resistance to Inversion}

The external and muscular moments acting at the ankle joint during gait have been analyzed in biomechanical terms. ${ }^{49}$ Using simplifying assumptions, the additional maximal volitional moment that was actively developed about the ankle by the evertor muscles in the present tests can be estimated (See "Appendix"). The percentage increase in moment supplied by evertor muscle activity can then be compared with that developed passively at $15^{\circ}$ of inversion using the three-quarter-top shoe alone or that shoe in combination with tape or an orthosis. We assumed that the maximal active isometric muscular moment developed about the ankle at $15^{\circ}$ of inversion remained unchanged under the different test conditions and that the maximal active isometric muscular moment was not affected by practice or fatigue because of the randomized testing sequences and the ample rest periods.

\section{Resolution and Repeatability}

The resolution of the measurement of strength was determined by the smallest increment in distance $(d), 2.5 \mathrm{~mm}$. This value is approximately $6 \%$ of the average maximal value of $d$. Tests of measurement repeatability were performed on three subjects for the ankle strength tests. Eversion strengths were measured to establish test variation between measurements made within the same day and also between measurements on 3 different days. The magnitude of the expected measurement variability was expressed by computing $95 \%$ confidence limits, and systematic variability was examined by a repeated-measures analysis of variance test (rm-ANOVA).

\section{Statistical Analyses}

Descriptive statistics were calculated for all variables. An rm-ANOVA was used to test the null hypothesis that shoe height (low-top versus three-quarter-top) had no effect on the magnitude of the external ankle moment that could be resisted in inversion at two different angles of ankle plantar flexion $\left(0^{\circ}, 32^{\circ}\right)$. An rm-ANOVA was also used to examine the effects of tape and orthoses relative to the unsupported states. Post hoc, two-sided, paired $t$-tests were used to test the magnitude and direction of any main effects using a $P$ value of 0.05 . Paired $t$-tests were also used to examine intrasubject differences between moments developed at the different ankle plantar flexion angles.

\section{RESULTS}

\section{Repeatability}

The 95\% confidence levels for the measured unipedal eversion strengths were \pm 1.51 and $\pm 1.91 \mathrm{~N}-\mathrm{m}$ in $0^{\circ}$ and $32^{\circ}$ ankle plantar flexion, respectively.

\section{Low-Top Shoe}

The data obtained with the low-top shoe without tape or any of the three orthoses indicate that the mean total (active + baseline) isometric moment that can maximally be developed by young adult men in resisting an inversion moment with the ankle in $15^{\circ}$ of inversion was $49.8 \pm 8.1$ $\mathrm{N}-\mathrm{m}$ (Table 1). This means that the normative values corresponding to $\pm 3 \mathrm{SD}$ values for healthy young adult

TABLE 1

Comparison of Mean (SD) Maximal Isometric Moments (in newton-meters) Resisted by Athletic Shoes at $15^{\circ}$ of Ankle Inversion ${ }^{a}$

\begin{tabular}{|c|c|c|c|c|c|}
\hline Plantar flexion angle & No support $t^{b}$ & Tape & Swede-O & Air-Stirrup & Sport-Stirrup \\
\hline \multicolumn{6}{|l|}{ Low-top shoe } \\
\hline $0^{\circ}$ & $49.8 \quad(8.1)$ & $53.9 \quad(9.2)$ & $54.7(10.1)$ & $53.8 \quad(9.5)$ & $53.2 \quad(9.9)$ \\
\hline $32^{\circ}$ & $58.5 \quad(8.1)$ & $60.9(10.0)$ & $62.0(10.8)$ & $60.4(10.1)$ & $61.4(10.7)$ \\
\hline \multicolumn{6}{|l|}{ Three-quarter-top shoe } \\
\hline $0^{\circ}$ & $55.6(11.9)$ & $60.7(12.6)$ & $60.6(11.9)$ & $60.0(11.9)$ & $60.7(14.0)$ \\
\hline $32^{\circ}$ & $61.7(12.3)$ & $64.8(11.0)$ & $65.5(10.8)$ & $64.8(10.3)$ & $65.5(11.8)$ \\
\hline
\end{tabular}

\footnotetext{
${ }^{a}$ Repeated-ANOVA tests demonstrated significant differences with respect to the low-top, no-support control state $(P=0.001)$
}

${ }^{b}$ For comparison, baseline resistance of the unsupported, weightbearing ankle was calculated as support $14 \mathrm{~N}$-m. 
men of this body size range from 25.5 to $74.0 \mathrm{~N}-\mathrm{m}$. As noted in the "Discussion," greater moments will immediately be developed if the evertor muscles contract under plyometric (forced lengthening) conditions because of short-range muscle stiffness.

Both the athletic tape and the ankle orthoses used in this study allowed participants to actively resist significantly greater inversion moments when compared with the low-top, no-tape control state at both $0^{\circ}$ and $32^{\circ}$ of ankle plantar flexion (rm-ANOVA, $P=0.001$ ) (Table 1). Paired $t$-tests revealed no significant differences between taping and any of the orthoses. At $0^{\circ}$ of ankle plantar flexion, the mean measured intraindividual increase in total resistance afforded passively by the different types of ankle support ranged from 3.4 to $4.9 \mathrm{~N}-\mathrm{m}$ (Table 2). At $32^{\circ}$ of ankle plantar flexion, the measured increases in total resistance ranged from 2.0 to $3.5 \mathrm{~N}-\mathrm{m}$. There was a trend that the Swede-O ankle brace provided the greatest increase in total resistance to an inversion moment at both $0^{\circ}$ and $32^{\circ}$ of ankle plantar flexion (Table 2). Larger total eversion moments were developed at $32^{\circ}$ than at $0^{\circ}$ of ankle plantar flexion with these devices (rm-ANOVA, $P<$ 0.001) (Table 1).

\section{Three-Quarter-Top Shoe}

When we compared the unsupported ankle with the ankle of a subject wearing a three-quarter-top shoe combined with taping or wearing one of three orthoses, the Swede-O ankle, Air-Stirrup, or the Sport-Stirrup, participants developed modestly greater total moments at both $0^{\circ}$ and $32^{\circ}$ ankle plantar flexion (rm-ANOVA, $P<0.001$ ) (Table 1). Paired $t$-tests revealed no significant differences between taping and any of the orthoses, however. At $0^{\circ}$ of ankle plantar flexion, the increase in active resistance as a result of wearing tape or a brace with the three-quarter-top shoe ranged from 4.3 to $5.1 \mathrm{~N}-\mathrm{m}$ (Table 2). At $0^{\circ}$ of ankle plantar flexion, athletic taping was associated with a greater increase in resistance to an inversion moment than any of the orthoses. At $32^{\circ}$ of ankle plantar flexion, however, the increases ranged from $4.5 \%(2.8 \mathrm{~N}-\mathrm{m})$ to $6.0 \%(3.7 \mathrm{~N}-\mathrm{m})$, with use of the Swede-O ankle brace leading to the greatest increase in total inversion resistance (Table 2). Again, larger moment values tended to be developed at $32^{\circ}$ than at $0^{\circ}$ of ankle plantar flexion (rm-ANOVA, $P<0.001$ ).

\section{Maximal Allowable Distance of the Ground-Reaction Force} from the Midline of the Foot

A simple static analysis of foot equilibrium predicts that the more medial a ground-reaction force is located relative to the midline of the foot, the larger the inversion moment it exerts about the ankle. Because of physiologic constraints, however, maximal isometric evertor strength limits the maximal distance that a given vertical static ground-reaction force can be located medial to the ankle. At $15^{\circ}$ of inversion, the present data demonstrated that the mean maximal permissible distances these young adult men could equilibrate the vertical ground-reaction force of $1 \mathrm{BW}$ medial to the midline of their shoe were $3.4 \pm 1.1 \mathrm{~cm}$ in a low-top shoe, $4.1 \pm 1.3 \mathrm{~cm}$ in a threequarter-top shoe, and $4.7 \pm 1.3 \mathrm{~cm}$ in a three-quarter-top shoe with a tape or brace.

\section{Effects of Shoe Height}

Wearing the three-quarter-top shoe significantly increased the maximal total moment resisted over that developed in the low-top shoe (rm-ANOVA, $P=0.012$ ). The increases were $5.9 \mathrm{~N}-\mathrm{m}(P=0.004)$ at $0^{\circ}$ of ankle plantar flexion and $3.3 \mathrm{~N}-\mathrm{m}(P=0.077)$ at $32^{\circ}$ of ankle plantar flexion (Tables 3 and 4). The average increases in resistance to moments obtained using tape or orthoses were similar in the low-top and three-quarter-top shoes: 4.1 and $4.8 \mathrm{~N}-\mathrm{m}$, respectively, at $0^{\circ}$ of ankle plantar flexion and 2.6 and $3.2 \mathrm{~N}-\mathrm{m}$, respectively, at $32^{\circ}$ of ankle plantar flexion. When results for both shoe types were averaged, the use of tape and orthoses resulted in a $7.8 \%$ increase in resistance to moments at $0^{\circ}$ of ankle plantar flexion and a $4.6 \%$ increase in total moment at $32^{\circ}$ of ankle plantar flexion. No significant interactions were found between the effects of shoe height and tape or type of brace (rm-ANOVA).

\section{Calculated Passive and Active Resistance to Inversion Moments}

The results of our calculations suggest that the active evertor muscle group can provide $35.8 \mathrm{~N}-\mathrm{m}$ of moment resistance, or 6.1 times the passive resistance that a three-quarter-top shoe can provide $(5.9 \mathrm{~N}$-m) and up to 3.3 times the resistance that an orthosis or athlete tape worn

TABLE 2

Comparison of Mean Paired Differences (in newton-meters) between the Maximal Eversion Moments Developed Wearing Ankle Supports Versus No Supports

\begin{tabular}{|c|c|c|c|c|c|}
\hline Shoe & $\begin{array}{l}\text { Plantar flexion } \\
\text { angle }\end{array}$ & Tape & Swede-O & Air-Stirrup & Sport-Stirrup \\
\hline \multirow{2}{*}{ Low-top } & $0^{\circ}$ & $4.2^{a}$ & $4.9^{a}$ & $4.0^{\alpha}$ & $3.4^{b}$ \\
\hline & $32^{\circ}$ & $2.4^{c}$ & $3.5^{b}$ & $2.0^{c}$ & $2.6^{c}$ \\
\hline \multirow{2}{*}{ Three-quarter-top } & $0^{\circ}$ & $5.1^{a}$ & $5.0^{\alpha}$ & $4.3^{a}$ & $4.8^{a}$ \\
\hline & $32^{\circ}$ & $3.1^{b}$ & $3.7^{\alpha}$ & $3.0^{c}$ & $2.8^{c}$ \\
\hline
\end{tabular}

${ }^{a}$ Significantly different from the unsupported control state $(P \leq 0.001)$.

${ }^{b}$ Significantly different from the unsupported control state $(P \leq 0.01)$.

c Significantly different from the unsupported control state $(P \leq 0.05)$. 
TABLE 3

Comparison of Mean Paired Differences (in newton-meters) between Low- and Three-quarter-Top Shoes in Maximally Resisting Ankle Inversion ${ }^{\alpha}$

\begin{tabular}{cccccc}
\hline Plantar flexion angle & No support & Tape & Swede-O & Air-Stirrup & Sport-Stirrup \\
\hline $0^{\circ}$ & 5.9 & $6.8^{b}$ & $5.9^{c}$ & $6.2^{b}$ & $7.5^{c}$ \\
$32^{\circ}$ & 3.3 & $4.0^{d}$ & $3.5^{c}$ & $4.3^{b}$ & $\mathbf{4 . 2}^{c}$ \\
\hline
\end{tabular}

${ }^{a}$ Calculated as intraindividual value of three-quarter-top shoe result minus low-top shoe result.

${ }^{b}$ Significantly different from the unsupported ankle $(P \leq 0.001)$.

${ }^{c}$ Significantly different from the unsupported ankle $(P \leq 0.01)$.

${ }^{a}$ Significantly different from the unsupported ankle $(P \leq 0.05)$.

TABLE 4

Effects of Active Evertor Muscles in the Isometric Protection of the Ankle at $15^{\circ}$ of Inversion ${ }^{a}$

\begin{tabular}{|c|c|c|c|c|c|c|}
\hline Factor & Isolated ankle & Three-quarter-top alone & \multicolumn{4}{|c|}{ Three-quarter-top shoe combined with } \\
\hline Passive contribution only ${ }^{b}$ & 1.00 & 1.42 & 1.78 & 1.77 & 1.73 & 1.76 \\
\hline
\end{tabular}

${ }^{a}$ Values expressed as ratios of moments (nondimensional units). All results for tests at $0^{\circ}$ plantar flexion.

${ }^{b}$ Calculated as $\left(M_{b}+M_{p}\right) / M_{b}$.

${ }^{c}$ Calculated as $\mathrm{M}_{\mathrm{t}} /\left(\mathrm{M}_{\mathrm{b}}\right)$.

inside a three-quarter-top shoe can provide $(5.9+5.1$ $\mathrm{N}-\mathrm{m})$ at $15^{\circ}$ of inversion. If the assumptions underlying the calculations are valid, then the average calculated increases in the baseline resistance of the unsupported ankle to an external inversion moment at $15^{\circ}$ of inversion and neutral ankle plantar flexion provided passively by the three-quarter-top shoe alone, the three-quarter-top shoe and tape, or the three-quarter-top shoe and orthosis were factors of $1.42,1.78$, and 1.77 , respectively (Table 4 ).

\section{DISCUSSION}

Despite the fact that ankle injuries are common from an epidemiologic point of view, and that they do recur in $70 \%$ to $80 \%$ of athletes, in any one athlete they usually only occur once every few years. ${ }^{44,50}$ For example, ankle sprains are the most common injury among competitive gymnasts, but that group, which trains about $20 \mathrm{hr} /$ week, incurred approximately 0.1 injuries per 1000 hours of practice. ${ }^{28}$ One might ask why do sprains occur so seldom? Indeed, given the number of times that a single limb is called on to resist supra-body weight ground-reaction forces during an hour of vigorous athletic activity, whether on level court surfaces or when running or turning on an uneven surface like a soccer field or trail, it is remarkable that more ankle injuries do not occur, especially in athletes wearing low-top shoes. This study addressed that question in the hope that it may lead to useful insights on the prevention of ankle injuries.

We will argue that the answer to the question of why there are not more ankle injuries is that under most circumstances the ankle is naturally protected from inversion injury by preplanned evertor muscle activity when landing. Indirect support for this hypothesis comes from our results, which show that at $15^{\circ}$ of inversion the evertor muscles can develop roughly three times larger moments than any of the present combinations of three-quarter-top shoe and tape or orthosis (Table 4), and up to six times more resistance to moments than the baseline resistance developed by the unprotected ankle in a low-top shoe (Table 1). However, on the occasions when the evertor muscles are either not recruited or are recruited too late to be of benefit in resisting ankle inversion injury, we calculate that these passive devices may help protect the ankle at $15^{\circ}$ of inversion by almost doubling its baseline resistance to further inversion. Because of the importance of active evertor muscles, athletes might be advised to strengthen the evertor muscles for sports that place them at risk for ankle inversion sprains.

There are several explanations for the failure of the evertor muscles to prevent an ankle inversion injury. After the delay due to neural latencies, which typically range from 85 to 90 msec until myoelectric activity is first observed, ${ }^{20,25}$ there is an additional delay because muscle contractile mechanics dictate that an additional $90 \mathrm{msec}$ is required by a muscle to develop contractile force to even half-maximal levels. ${ }^{38,45}$ How do these times compare with the range of times required to sprain an ankle in inversion?

Because the vertical ground-reaction force peaks at about 40 msec when landing from a jump, ${ }^{7}$ one can estimate the worst-case scenario to be about $40 \mathrm{msec}^{36}$ to invert the ankle to about $10^{\circ},{ }^{20}$ the time of the first observable myoelectric activity in response to ankle inversion. Depending on the magnitude and rate of application of the inversion moment and the range of ankle motion involved, inversion times may therefore range from 40 to several hundred milliseconds. In the case that ankle inversion rotation occurs in less than $100 \mathrm{msec}$, it is clear from the two consecutive time delays previously noted ( 85 and $90 \mathrm{msec}$ ) that the evertor muscles must be activated before the onset of the external forces during footstrike. This preactivation is needed so that an ankle muscle cocontraction can develop sufficient force in the evertor mus- 
cle to prevent injury $40 \mathrm{msec}$ after footstrike. Such preactivation is usual, for example, before foot contact when walking down stairs ${ }^{17,34}$ and when landing after a jump. ${ }^{8}$ In both activities, the calf muscle activity started approximately $150 \mathrm{msec}$ before landing and activity increased up to footstrike. Landing with a single limb on an unseen object, such as an opponent's basketball shoe, a stray tennis ball, or a large pebble will lead to ground recontact earlier than anticipated, yielding inadequate time for the development of sufficient evertor muscle tension to prevent forced inversion.

A germane observation about premature ground contact was made by Melville-Jones and Watt. ${ }^{34,35}$ These investigators found that when subjects were suspended by a harness above the ground and dropped without warning through heights of less than $9 \mathrm{~cm}$ without being able to see the floor, they landed with higher peak ground impact reaction forces than when landing from greater heights. They found the first detectable calf muscle myoelectric activity occurred $74 \mathrm{msec}$ after the start of the drop (because of vestibular reflexes), and the first appreciable ankle muscle tension occurred some $102 \mathrm{msec}$ after the subject was released and had fallen approximately $5 \mathrm{~cm}$. In other words, it may be more difficult to actively prevent an inversion sprain when the foot drops less than $10 \mathrm{~cm}$ compared with more than $10 \mathrm{~cm}$ because there simply is not adequate time for the ankle evertor muscle co-contraction to develop sufficient tension, particularly when landing with an extended knee, which tends to increase the ground-reaction force. ${ }^{7}$ This fact might be used in educational interventions aimed at reducing ankle injuries from landing on foreign objects by teaching players when they are off the ground to co-contract their ankle muscles and flex their knees when they anticipate that the instant of retouching the ground will be unpredictable.

Muscle stiffness in the co-contracted dorsiflexors, a muscle group with anatomic similarities to the evertors, has been shown to increase fivefold, from $0.5 \mathrm{~N}-\mathrm{m} / \mathrm{deg}$ at rest to approximately $2.5 \mathrm{~N}-\mathrm{m} / \mathrm{deg}$ at a half-maximal contraction level. ${ }^{43}$ One final advantage of a fully established evertor co-contraction is that in a plyometric contraction, until the crossbridges are broken, the short-range evertor muscle stiffness will provide considerable muscular resistance to rapid inversion without any time delay. ${ }^{8}$

If maximal eversion strength is developed, then when the ground-reaction force exceeds $1 \mathrm{BW}$ our results show the maximal distance that a vertical ground-reaction force of $1 \mathrm{BW}$ magnitude can be located medially relative to the midline of the foot will decrease in proportion to the amount that the ground-reaction force exceeds body weight. For example, we found that under static conditions in a low-top shoe, the maximal distance a vertical ground-reaction force of $1 \mathrm{BW}$ can be located medial to the midline of the near-maximally inverted foot averages 3.4 $\mathrm{cm}$. If that ground-reaction force should lie medial to that $3.4 \mathrm{~cm}$ margin, then forced inversion will result despite maximal evertor muscle contraction. It will certainly occur if the establishment of that maximal contraction is tardy. If the magnitude of the ground-reaction force is increased by $50 \%$, such as it is while carrying a heavy load or during running, ${ }^{50}$ this quasistatic analysis shows that the mean allowable distance in young men is reduced by two-thirds, to $2.3 \mathrm{~cm}$. Moreover, peak ground-reaction forces of four times body weight are not unusual when landing from a jump ${ }^{7,8}$; therefore, from the results presented in this paper, the maximal allowable distance of the $4 \mathrm{BW}$ ground-reaction force medial to the foot midline would be as little as $0.85 \mathrm{~cm}$ in a low-top shoe and $1.2 \mathrm{~cm}$ in a three-quarter-top shoe when wearing tape or a brace. Because of such small margins, it should not be surprising that landing unexpectedly on someone else's foot or another hard object under the medial border of one's shoe can lead to an ankle inversion injury, particularly with a straightened knee. ${ }^{7}$

In this study, we provide the estimates of the degree to which the fully activated evertor muscle group can augment the passive resistance of the fully loaded ankle at an inversion angle of $15^{\circ}$ without the benefit of high-top shoes, ankle orthoses, athletic tape, or combinations of the three. The $15^{\circ}$ angle was selected because it is within $2^{\circ}$ of the average active range of ankle inversion $\left(17^{\circ}\right)$ measured in the young adult male population. ${ }^{38}$ The position of the ankle in the athlete while airborne usually reflects the ankle's position on leaving the ground, so it is the maximal active angle of inversion achieved in the air that is the worst-case initial scenario on initial ground recontact. This paper addressed that scenario at footstrike by quantifying the passive and active factors acting to arrest further (forced) ankle inversion at $15^{\circ}$ of inversion. It is likely, however, that extrapolation of the present results beyond $15^{\circ}$ of inversion may underestimate the increase in the passive resistance of molded ankle orthoses because their stiffnesses likely increase nonlinearly because of the semirigid plastic shells. Exactly how much moment the orthoses can develop to protect a weightbearing inverted ankle from injury is presently unknown. In the case of tape, the linear extrapolation may be better because the stiffness of the taped ankle does not appear to change appreciably beyond $15^{\circ}$ of inversion. ${ }^{39}$

This study provides data on the maximal voluntary isometric strength of the evertor muscles in healthy young men with the ankles in $15^{\circ}$ of inversion. Those experimental data are reliable and independent of any of the later modeling assumptions. The measured strengths were markedly more than those measured using the same methods with the ankle in the neutral position, a strength difference that reflects the length-tension relationship of the evertor muscles. ${ }^{38}$ In our earlier study, the evertor muscles developed an average maximal moment of 21.9 $\mathrm{N}-\mathrm{m}$ at $0^{\circ}$ of ankle plantar flexion in the neutral ankle position, or only $43.9 \%$ of the total resistance to inversion $(49.8 \mathrm{~N}-\mathrm{m})$ we measured in the present study at $15^{\circ}$ of inversion. ${ }^{39}$ Because we have estimated that $14.0 \mathrm{~N}-\mathrm{m}$ of the resistance measured at $15^{\circ}$ of inversion was mostly due to passive tissue elongation, the remaining $35.8 \mathrm{~N}-\mathrm{m}$ (calculated from 49.8 minus $14.0 \mathrm{~N}-\mathrm{m}$ ) is most likely due to the maximally active evertor muscles (Table 1). Thus, the muscular contribution to the moment resistance has increased $63 \%$ from 21.9 to $35.8 \mathrm{~N}$-m from the neutral position to the $15^{\circ}$ inversion position. At $32^{\circ}$ of ankle 
plantar flexion, the corresponding increase is estimated from Table 1 to be $73 \%$ at a moment of $44.5 \mathrm{~N}-\mathrm{m}$ (calculated by subtracting $14.0 \mathrm{~N}-\mathrm{m}$ from $58.5 \mathrm{~N}-\mathrm{m}$ ). These increases are consistent with the $45 \%$ increase observed due to lengthening dorsiflexors of young adults. ${ }^{46}$

We can use the present results to estimate muscle forcevelocity effects occurring in dynamic forced inversion in the following manner. We again assumed the ankle is forcibly rotated from neutral to $15^{\circ}$ of inversion, and we subtracted the $14.0 \mathrm{~N}-\mathrm{m}$ baseline resistance developed. During further inversion, active evertor muscles will undergo a plyometric contraction. From the aforementioned argument at $0^{\circ}$ of ankle plantar flexion and $15^{\circ}$ of inversion, we estimated that the isometric muscle contribution amounted to $35.8 \mathrm{~N}-\mathrm{m}$. From this quantity, we can estimate the increase in evertor moment contribution in a plyometric evertor muscle contraction because in small rodents, for example, electrically stimulated muscle force has been reported to increase from between $38 \%$ to $80 \%$ above the measured isometric values, depending on muscle architecture, operating length, and strain rates. ${ }^{33,47,48}$ Thus, a conservative estimate of a $50 \%$ increase in evertor force due to rapid lengthening would result in a total active and passive resistance of $35.8+35.8 \times 0.5+14.0$ or $68.0 \mathrm{~N}-\mathrm{m}$, a value not very different from the maximal total resistance found in the present study when the men wore the combination of devices that afforded the best ankle protection. Given the results of a recent study ${ }^{24}$ showing that at $15^{\circ}$ of inversion the peroneus longus and brevis muscles have an average lever arm of $21 \mathrm{~mm}$ (and ignoring the possible $5 \mathrm{~mm}$ lever arm of the triceps surae muscle), one can estimate maximal total equivalent muscle force for the evertor muscles as $53.7 \mathrm{~N}-\mathrm{m} / 0.0212 \mathrm{~m}$, or $2533 \mathrm{~N}$. The fact that the peroneal tendon can rupture during a sprain is additional evidence that the rapid plyometric contraction associated with forced inversion can generate substantial tension in a fully contracted evertor muscle. ${ }^{4,23}$

The measurements of total resistance to inversion under the various experimental conditions would appear reliable because we found adequate test-retest reliability and consistency with previous results (Tables 1 through $3)^{38}$ The tape results only hold for similar wrapping methods using tape of similar tensile stiffness to that used in this study - tape stiffness can vary fourfold. ${ }^{39}$ Our method for partitioning resistance to inversion into baseline, passive, and active quantities has its limitations (Table 4). The first is that the measurement of "passive" ankle stiffness was not made in the same young male subject group as were the present ankle strength measures. However, because the subject populations were similar and mean values of ankle passive stiffness ( 0.9 to $1.0 \mathrm{~N}-\mathrm{m} / \mathrm{deg}$ ) found in two independent studies were consistent to within $7.5 \%$, those stiffness values seem reliable. ${ }^{27,36} \mathrm{~A}+2 \mathrm{SD}$ value of stiffness would increase this value by less than $50 \%$ and not alter the main findings of the study. From those values, we estimated ankle joint baseline stiffness at $15^{\circ}$ of inversion by assuming linear elastic behavior between $0^{\circ}$ and $15^{\circ}$ of inversion; this is not an unreasonable assumption and probably involves an error of not more than $20 \%$. The assumption that the maximal active eversion moment generated by muscles is similar for tests conducted with and without tape or orthoses seems reasonable. It is unlikely to exceed the $29 \%$ difference between low- and three-quarter-top shoes already observed at $0^{\circ}$ of inversion ${ }^{38}$; and a difference of this magnitude would not alter the study conclusions.

In this study, we chose to analyze the state of affairs just before full inversion is reached because, if injury is to be avoided with certainty, further inversion must be arrested by muscle, shoe, tape, or orthosis within the normal range of motion. It should be noted that our measurements of total resistance to inversion were quasistatic, in contrast to the dynamic nature of most ankle injuries, but we have discussed the magnitude of the potential increase in evertor muscle moment under plyometric conditions. Lastly, the fact that we only used freshly applied tape means that the results are the best that can be hoped for with standard taping techniques. The decrement in the external support offered the weightbearing ankle by adhesive athletic tape with increasing exercise duration is the focus of a companion study. ${ }^{30}$

The results suggest that the greatest effect of tape or ankle orthoses is to improve resistance to inversion moments whenever the evertor muscles are inactive (Table 4). These findings are consistent with the findings of Shapiro et al., ${ }^{42}$ who showed a twofold reduction of passive movement for a taped or braced ankle with a high-top shoe as compared with an unprotected ankle in a low-top shoe.

\section{CONCLUSIONS}

1. For an adult male ankle at $15^{\circ}$ of inversion, the fully active evertor muscles, acting isometrically, can provide more than three times greater protection against an ankle inversion injury than tape or an orthosis worn inside a three-quarter-top shoe.

2. At $15^{\circ}$ of inversion no meaningful differences were found in the total eversion moments developed in the taped or braced ankle in the low-top shoe; similar results were obtained for the three-quarter-top shoe.

3. When the evertor muscles are inactive, calculations show a three-quarter-top shoe will increase the baseline resistance to inversion by a factor of 1.42 ( or $6 \mathrm{~N}-\mathrm{m}$ ); when the shoe is worn with the orthoses or tape used in this investigation, the support will increase the baseline ankle resistance by a factor of 1.77 (or $11 \mathrm{~N}-\mathrm{m}$ ). The choice between the type of support can therefore be made on the basis of comfort, convenience, and cost.

4. Precontracted and strong evertor muscles appear to be the most effective form of ankle protection at footstrike.

\section{ACKNOWLEDGMENTS}

We thank the participants for their time and efforts. We acknowledge the financial support of National Institute of Health (Bethesda, Maryland) grants R01 AG 10542 and P30 AG 08808 and support from the University of Michigan Medical School's Student Biomedical Research Program. We would also like to thank Shane Easterling, ATC, 
for his contributions in applying the athletic tape, and Paul Moga and Laurie Huston for helping to measure the location of the subtalar instantaneous center of rotations from radiographs.

\section{REFERENCES}

1. Barrett JR, Tanji JL, Drake C: High- versus low-top shoes for the prevention of ankle sprains in basketball players: A prospective, randomized study. Am J Sports Med 21: 582-585, 1993

2. Bennell KL, Goldie PA: The differential effects of external ankle support on postural control. J Orthop Sports Phys Ther 20: 287-295, 1994

3. Burks RT, Bean BG, Marcus R, et al: Analysis of athletic performance with prophylactic ankle devices. Am J Sports Med 19: 104-106, 1991

4. Cachia VV, Grumbine NA, Santoro JP, et al: Spontaneous rupture of the peroneus longus tendon with fracture of the os peroneum. J Foot Surg 27: 328-333, 1988

5. Chen J, Siegler S, Schneck CD: The three-dimensional kinematics and flexibility characteristics of the human ankle and subtalar joint. Part II: Flexibility characteristics. J Biomech Eng 110: 374-385, 1988

6. Colville MR, Marder RA, Boyle JJ, et al: Strain measurement in lateral ankle ligaments. Am J Sports Med 18: 196-200, 1990

7. Dufek JS, Bates BT: Biomechanical factors associated with injury during landing during sports. Sports Med 12: 326-337, 1991

8. Dyhre-Poulsen $\mathrm{P}$, Simonsen ER, Voigt $\mathrm{M}$ : Dynamic control of muscle stiffness and $\mathrm{H}$ reflex modulation during hopping and jumping in man. J Physiol (Lond) 437: 287-304, 1991

9. Firer $P$ : Effectiveness of taping for prevention of ankle ligament sprains. Br J Sports Med 24: 47-50, 1990

10. Fridén $T$, Zätterström $R$, Lindstrand $A$, et al: $A$ stabilometric technique for evaluation of lower limb instabilities. Am J Sports Med 17: 118-122, 1989

11. Fumich RM, Ellison AE, Guerin GJ, et al: The measured effect of taping on combined foot and ankle motion before and after exercise. Am $J$ Sports Med 9: 165-170, 1981

12. Garrick JG: The frequency of injury, mechanism of injury, and epidemiology of ankle sprains. Am J Sports Med 5: 241-242, 1977

13. Garrick JG, Requa RK: The epidemiology of foot and ankle injuries in sports. Clin Sports Med 7: 29-36, 1988

14. Garrick JG, Requa RK: Role of external support in the prevention of ankle sprains. Med Sci Sports 5: 200-203, 1973

15. Glick JM, Gordon RB, Nishimoto D: The prevention and treatment of ankle injuries. Am J Sports Med 4: 136-141, 1976

16. Greene TA, Hillman SK: Comparison of support provided by a semirigid orthosis and adhesive ankle taping before, during, and after exercise. Am J Sports Med 18: 498-506, 1990

17. Greenwood $\mathrm{A}$, Hopkins A: Landing from an unexpected fall and a voluntary step. Brain 99: 375-386, 1976

18. Gross MT, Ballard CL, Mears HG, et al: Comparison of DonJoy ankle ligament protector and Aircast Sport-Stirrup orthoses in restricting foot and ankle motion before and after exercise. J Orthop Sports Phys Ther 16 : $60-67,1992$

19. Gross MT, Bradshaw MK, Ventry LC, et al: Comparison of support provided by ankle taping and semirigid orthosis. J Orthop Sports Phys Ther 9: 33-39, 1987

20. Huber BH, Gottlieb DJ, Roos EM, et al: Muscle reaction and joint motion changes in chronically unstable ankle. Trans Orthop Res Soc 21: 268, 1996

21. Juvenal JP: The effects of ankle taping on vertical jumping ability. Athl Train 7: 146-149, 1972

22. Karlsson J, Andreasson GO: The effect of external ankle support in chronic lateral ankle joint instability: An electromyographic study. Am J Sports Med 20: 257-261, 1992

23. Kilkelly FX, McHale KA: Acute rupture of the peroneal longus tendon in a runner: A case report and review of the literature. Foot Ankle int 15: $567-569,1994$

24. Klein P, Mattys S, Rooze M: Moment arm length variations of selected muscles acting on talocrural and subtalar joints during movement: $A n$ in vitro study. J Biomech 29: 21-30, 1996

25. Konradsen L, Ravn JB: Ankle instability caused by prolonged peroneal reaction time. Acta Orthop Scand 61: 388-390, 1990

26. Laughman RK, Carr TA, Chao EY, et al: Three-dimensional kinematics of the taped ankle before and after exercise. Am J Sports Med 8: 425-431, 1980

27. Lee SG: Effect of age on ankle stiffness, strength, and rate of torque development in inversion and eversion, in Theoretical and Experimental Analyses of the Effects of Age and Peripheral Neuropathy on Unipedal Balance. Dissertation, Department of Mechanical Engineering \& Applied Mechanics, University of Michigan, Ann Arbor, Michigan, 1993
28. Lindner KJ, Caine DJ: Injury patterns of female competitive club gymnasts. Can J Sports Sci 15: 254-261, 1990

29. Mack RP: Ankle injuries in athletics. Clin Sports Med 1: 71-84, 1982

30. Manfroy PP, Ashton-Miller JA, Wojtys EM: The effect of exercise, prewrap and athletic tape on the maximum active and passive ankle resistance in ankle inversion. Am J Sports Med, in press, 1996

31. Mayhew JL: Effects of ankle taping on motor performance. Athl Train 7: $10-11,1972$

32. McCluskey GM, Blackburn TA Jr, Lewis T: Prevention of ankle sprains. Am J Sports Med 4: 151-157, 1976

33. McCully KK, Faulkner JA: Characteristics of lengthening contractions associated with injury to skeletal muscle fibers. J Appl Physiol 61: 293299,1986

34. Melville-Jones GM, Watt DG: Observations on the control of stepping and hopping movements in man. J Physiol (Lond) 219: 709-727, 1971

35. Melville-Jones GM, Watt DG: Muscular control of landing from unexpected falls in man. J Physiol (Lond) 219: 729-737, 1971

36. Mizrahi J, Ramot $Y$, Susak $Z$ : The dynamics of the subtalar joint in sudden inversion of the foot. J Biomech Eng 112: 9-14, 1990

37. Morris $\mathrm{HH}$, Musnicki W III: The effect of taping on ankle mobility following moderate exercise. J Sports Med Phys Fitness 23: 422-426, 1983

38. Ottaviani RA, Ashton-Miller JA, Kothari SU, et al: Basketball shoe height and the maximal muscular resistance to applied ankle inversion and eversion moments. Am J Sports Med 23: 418-423, 1995

39. Pope MH, Renstrom P, Donnermeyer D, et al: A comparison of ankle taping methods. Med Sci Sports Exerc 19: 143-147, 1987

40. Rarick GL, Bigley G, Karst R, et al: The measurable support of the ankle joint by conventional methods of taping. $J$ Bone Joint Surg 44A: 11831190,1962

41. Rovere GD, Clarke TJ, Yates CS, et al: Retrospective comparison of taping and ankle stabilizers in preventing ankle injuries. Am J Sports Med 16: 228-233, 1988

42. Shapiro MS, Kabo JM, Mitchell PW, et al: Ankle sprain prophylaxis: An analysis of the stabilizing effects of braces and tape. Am J Sports Med 22: $78-82,1994$

43. Sinkjaer $T$, Toft $E$, Andreassen $S$, et al: Muscle stiffness in human ankle dorsiflexors: Intrinsic and reflex components. I Neurophysiol 60: 11101121, 1988

44. Smith RW, Reischl SF: Treatment of ankle sprains in young athletes. Am J Sports Med 14: 465-471, 1986

45. Thelen DG, Schultz AB, Alexander NB, et al: Effects of age on rapid ankle torque development. J Gerontol 51A: M226-232, 1996

46. van Schaik CS, Hicks AL, McCartney N: An evaluation of the lengthtension relationship in elderly human ankle dorsiflexors. $J$ Gerontol 49: B121-B127, 1994

47. Warren GL, Hayes DA, Lowe DA, et al: Mechanical factors in the initiation of eccentric contraction-induced injury in rat soleus muscle. $J$ Physiol (Lond) 464: 457-475, 1993

48. Warren GL, Hayes DA, Lowe DA, et al: Materials fatigue initiates eccentric contraction-induced injury in rat soleus muscle. J Physiol (Lond) 464 : 477-489, 1993

49. Winter DA: The Biomechanics and Motor Control of Human Gait: Normal, Elderly and Pathology. Second edition. University of Waterloo Press, Waterloo, 1991

50. Yeung MS, Chan $\mathrm{KM}$, So $\mathrm{CH}$, et al: An epidemiological survey on ankle sprain. Br J Sports Med 28: 112-116, 1994

\section{APPENDIX}

Using a quasistatic biomechanical analysis, the maximal voluntary total isometric eversion moment $\left(M_{\mathrm{t}}\right)$ measured in this experiment at $15^{\circ}$ of inversion can be partitioned into three components. The first component is the baseline moment $\left(M_{\mathrm{b}}\right)$ developed by all internal passive tissues placed under tensile strain and crossing the ankle joint during quiet unipedal stance, as well as any evertor postural muscle tone during weightbearing. The second component is the moment $\left(M_{\mathrm{a}}\right)$ developed by maximally contracting muscles crossing the joint. The third component is the passive moment $\left(M_{\mathrm{p}}\right)$, developed by any external devices (three-quarter-top shoe, tape, or one of the three orthoses) crossing the ankle. We assume in this simplified quasistatic analysis that any ankle moment due to the lateral acceleration of the ankle joint is 
negligible. The relationship between the various moments during these maximal strength tests is given by:

$$
M_{\mathrm{t}}=M_{\mathrm{b}}+M_{\mathrm{p}}+M_{\mathrm{a}}
$$

where $M_{\mathrm{p}}=0$ when no external device is worn.

Thus, the moment component contributed by the active evertor muscles is given by:

$$
M_{\mathrm{a}}=M_{\mathrm{t}}-M_{\mathrm{p}}-M_{\mathrm{b}}
$$

We shall assume $M_{\mathrm{b}}$, the baseline resistance of the isolated weightbearing ankle joint at $15^{\circ}$ of inversion in the low-top shoe, has a constant value of $14 \mathrm{~N}$-m under all the present test conditions (see "Materials and Methods"). Hence, the contribution of a particular external device $\left(M_{p}\right)$ can be estimated from the difference in $M_{\mathrm{t}}$ measured with and without the device, if one assumes $M_{\mathrm{a}}$ remains unchanged during each maximal strength test. The increase in passive resistance offered by the three-quarter-top shoe, three-quarter-top shoe and tape, or three-quarter-top shoe and orthosis over that in the low-top shoe is calculated from the ratio $M_{\mathrm{p}} / M_{\mathrm{b}}$. This increase in passive resistance to inversion can be directly compared with that developed by the evertor muscles when they are isometrically maximally active, and is calculated from the ratio $M_{2} / M_{\mathrm{b}}$. 